\title{
Pituitary Centers of Excellence
}

Nancy McLaughlin, MD, PhD*

Edward R. Laws, MD $\ddagger$

Nelson M. Oyesiku, MD, PhD§

Laurence Katznelson, MDף

Daniel F. Kelly, MD*

*Brain Tumor Center \& Pituitary Disorders Program, John Wayne Cancer Institute at Saint John's Health Center, Santa Monica, California; $\ddagger$ Pituitary and Neuroendocrine Center, Department of Neurosurgery, Brigham and Women's Hospital, Boston, Massachusetts; §Pituitary Center and Department of Neurosurgery, Emory University, Atlanta, Georgia; \Pituitary Center and Departments of Neurosurgery and Medicine, Stanford University School of Medicine, Palo Alto, California

\section{Correspondence:}

Daniel F. Kelly, MD,

Brain Tumor Center,

John Wayne Cancer Institute at Saint

John's Health Center,

2200 Santa Monica Blvd.,

Santa Monica, CA 90404

E-mail: kellyd@jwci.org

Received, August 31, 2011

Accepted, July 7, 2012

Published Online, August 16, 2012.

Copyright (C) 2012 by the Congress of Neurological Surgeons

Pituitary tumors and associated neuroendocrine disorders pose significant challenges in diagnostic and therapeutic management. Optimal care of the "pituitary patient" is best provided in a multidisciplinary collaborative environment that includes not only experienced pituitary practitioners in neurosurgery and endocrinology, but also in otorhinolaryngological surgery, radiation oncology, medical oncology, neuro-ophthalmology, diagnostic and interventional neuroradiology, and neuropathology. We provide the background and rationale for recognizing pituitary centers of excellence and suggest a voluntary verification process, similar to that used by the American College of Surgeons for Trauma Center verification. We propose that pituitary centers of excellence should fulfill 3 key missions: (1) provide comprehensive care and support to patients with pituitary disorders; (2) provide residency training, fellowship training, and/or continuing medical education in the management of pituitary and neuroendocrine disease; and (3) contribute to research in pituitary disorders. As this is a preliminary proposal, we recognize several issues that warrant further consideration including center and surgeon practice volume as well as oversight of the verification process.

KEY WORDS: Center of excellence, Endonasal endoscopic surgery, Multidisciplinary treatment, Pituitary adenoma, Transsphenoidal surgery, Training

Neurosurgery 71:916-926, 2012

DOI: $10.1227 /$ NEU.0b013e31826d5d06

www.neurosurgery-online.com

$\mathbf{T}$ he term center of excellence (COE) has been used in various fields of medicine and is already widely used in the field of pituitary disorders. A search of the term pituitary center of excellence using Google's search engine provides more than 23000 results. Currently, the term pituitary COE is self-designated by individual centers without defined criteria or a certification process. Such labeling may be warranted; however, in other instances, it may inspire patient confidence in centers or practitioners without an established track record in pituitary tumor management. In the present era when Internetbased searches can have a major influence on patients' medical care decisions, ${ }^{1,2}$ establishing objective and verifiable criteria for designation as a pituitary COE would be beneficial for patients and elevate standards for centers that strive for excellence in the care of pituitary patients. We review the literature supporting the establishment of pituitary COEs, suggest criteria for

ABBREVIATIONS: ACGME, Accreditation Council for Graduate Medical Education; ACS, American College of Surgeons; COE, center of excellence
COE recognition, consider the development of standards of care, and discuss potential pitfalls.

\section{HIGH PREVALENCE AND IMPACT OF PITUITARY TUMORS WARRANT COE DEVELOPMENT}

Contemporary studies indicate that pituitary tumors are far more common than previously thought. Several recent population-based studies estimated the prevalence of pituitary adenomas. The largest meta-analysis on pituitary adenoma prevalence by Ezzat et $\mathrm{al}^{3}$ found an overall estimated prevalence of $16.7 \%$ ( 1 in 6 individuals), including $14.4 \%$ in autopsy studies (range, $1 \%-40 \%)$ and $22.5 \%$ in radiological studies (range, 1\%-35\%). Three recent studies of clinically relevant pituitary adenomas from Belgium, ${ }^{4}$ Switzerland, ${ }^{5}$ and the United Kingdom ${ }^{6}$ documented relatively consistent prevalence rates of $94,80.5$, and 77.6 cases per 100000 population, respectively (or 1 case per 1064, 1241, and 1288 individuals, respectively) (Table 1). These 3 studies suggest that clinically relevant pituitary adenomas are likely to be prevalent at a rate of almost 1 per 1000 individuals worldwide. Three 


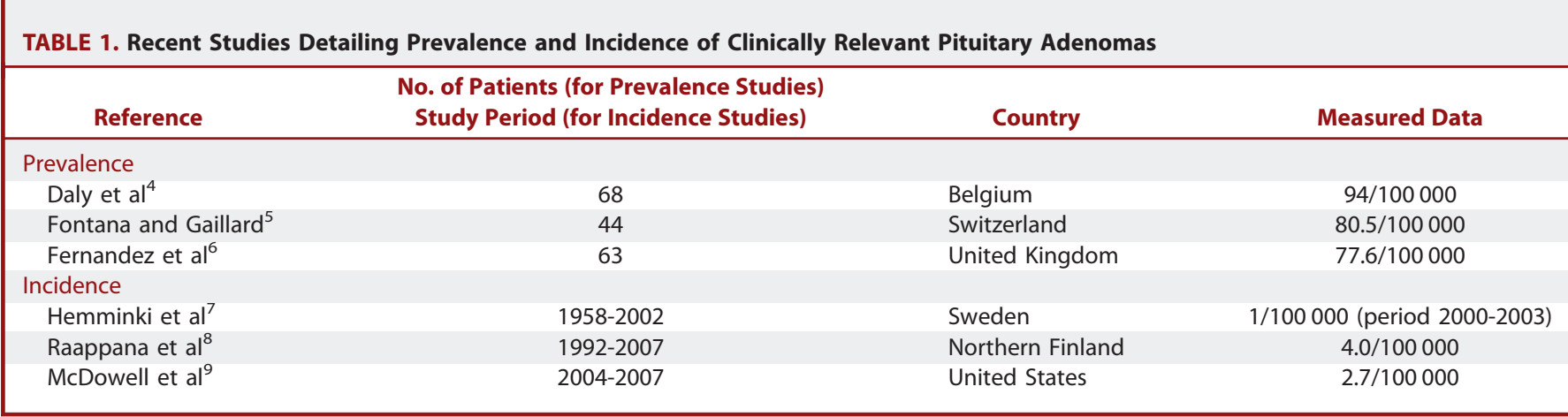

recent studies addressing the incidence of newly diagnosed clinically active pituitary adenomas from Sweden, ${ }^{7}$ Finland, ${ }^{8}$ and the United States ${ }^{9}$ also documented fairly consistent rates of 1 to 4 in a population of 100000 per year.

The spectrum of the clinical presentation of pituitary adenomas and other parasellar tumors is wide, and the sequelae of hormonal and neurological derangements can severely impair quality of life and shorten lifespan. ${ }^{10-17}$ Although pituitary adenomas and related lesions such as craniopharyngiomas are generally considered histologically benign, invasive and aggressive subtypes do occur, and disease control, particularly for endocrine-active pituitary adenomas and craniopharyngiomas, often requires multimodality treatment, which may include surgery, medical therapy, hormone replacement, and radiotherapy or radiosurgery. Given the high prevalence of pituitary tumors and the complexity of their diagnosis and management, there is a need to increase awareness within the medical community and lay public about the impact of pituitary tumors and related hormonal disorders. There is also a need to facilitate timely and appropriate diagnostic evaluation for patients and help them find experienced pituitary specialists for optimal care. These objectives may be ideally met on broad scale by creating pituitary COE criteria based on a clinical track record in pituitary patient care, as well as in training and educational activities and pituitary-related research.

\section{HISTORY OF COEs}

The term COE has been given numerous definitions, without clear consensus on its meaning. For the purposes of this discussion, we define a COE as a cohesive team of specialists who promote collaboration and apply best practices in a specific focus area to improve results and overall outcomes. In the United States, the term COE was first associated with a health care-related organization in 1991 when the Centers for Medicare and Medicaid Services started its Medicare Participating Heart Bypass Center Demonstration project. Initially, designation as a COE was focused on lowering health care costs as its primary goal. ${ }^{18}$ In
1996, Centers for Medicare and Medicaid Services attempted to extend this negotiated package price to patients undergoing total joint replacement. However, this proposition was opposed by the American Academy of Orthopedic Surgeons, affirming that "there is no conclusive evidence showing that participating centers are better providers of care than nonparticipating facilities." ${ }^{\prime 18}$ This project was finally abandoned in 2002 in part because the agency's proposed bundled payment was so low that it did not cover either physician or hospital costs.

Another example is the National COE in Women's Health established in 1996 by the US Department of Health and Human Services. ${ }^{19}$ To be recognized as such, the center had to link an academic program with medical specialties to improve care for women, promote research in women's health issues, improve education for health care providers, and promote programs to serve the underserved. ${ }^{19}$ From 1996 to 2007, more than 20 centers were designated as COEs in women's health. However, since the end of this federal program, there has been no formal re-evaluation by the US Department of Health and Human Services to assess maintenance of this recognition.

A current active model of COE in medicine is that of bariatric surgery. ${ }^{20}$ The American Society of Bariatric Surgery and the American College of Surgeons launched the COE Programs aimed at identifying practices, surgeons, and institutions able to deliver care to bariatric patients in the safest and most efficient way. ${ }^{21,22}$ In 2006, Centers for Medicare and Medicaid Services established a national coverage policy for bariatric surgery. The American Society of Bariatric Surgery has contracted the Surgical Review Corporation, a private entity third party to evaluate the applications from various centers. ${ }^{23}$ The review committee grants a provisional status valid for 2 years if the applying center fulfills all 10 requirements as detailed in Table 2 . Before the end of the provisional status, health centers are encouraged to submit an application for full approval as an American Society for Metabolic and Bariatric Surgery Bariatric Surgery COE. In this specific example, patients requiring bariatric surgery and the payer are empowered to choose a surgeon with an excellent track record and compare outcome data with benchmark standards. ${ }^{24}$ 


$\begin{aligned} & \text { TABLE } \\
& \text { Surgery }\end{aligned}$ Bariatric Surgery Center of Excellence Criteria ${ }^{a}$
\begin{tabular}{ll} 
Criteria & \multicolumn{1}{c}{ Description } \\
\hline 1 & Institutional commitment to excellence \\
2 & $\begin{array}{c}\text { Surgical experience and volumes determined by the ASBS } \\
\text { and ACS }\end{array}$ \\
3 & Designated medical director \\
4 & Responsive critical care support \\
5 & Appropriate equipment and instruments \\
6 & Surgeon dedication and qualified call coverage \\
7 & Clinical pathways and standard operating procedures \\
8 & Specialized nurses, physician extenders, and program \\
& coordinator \\
9 & Patient support group \\
10 & Long-term patient follow-up with longitudinal database
\end{tabular}

${ }^{a}$ ASBS, American Society of Bariatric Surgery; ACS, American College of Surgeons

Other examples of effective implementation of COEs on a national scale are the designation of trauma centers and systems as well as Stroke Centers. Trauma Centers are examples of the verification model. The American College of Surgeons (ACS) established in the 1970s guidelines for the development, operation, and verification of trauma centers and systems. This effort focused on multispecialty surgical and critical care teams at designated medical centers with strict criteria for Level I to IV trauma centers. The benefits of this highly regulated and monitored program have been extensively documented in the literature, both nationally and internationally, initially in terms of mortality but also morbidity for trauma victims and particularly for patients with moderate and severe head injury. ${ }^{25-29}$ Although the designation of a trauma center is determined by individual state law provisions, the ACS ranks trauma centers (Levels I-IV) based on specific criteria including a minimum required volume of severely injured patients, the availability of a certain number of surgeons/emergency physicians/ anesthesiologists, the presence of an education program as well as preventive and outreach programs (for Level I centers). Consultation and verification programs directed by the ACS allow regular validation of resources available at trauma centers. Establishment of trauma centers has helped to build contemporary national registries tabulating outcome measures throughout the continuum of care for this patient population, leading to national norms and standards for trauma outcomes. Verified trauma centers are unequivocally viewed as an indispensable component of our health care system.

In 2000, the Brain Attack Coalition identified key elements that stroke centers should include. The Brain Attack Coalition developed recommendations for the establishment and operation of primary and comprehensive stroke centers to improve the medical care of patients with strokes. ${ }^{30,31}$ In 2003, the Primary Stroke Center Certification Program, developed in collaboration with the American Heart Association/American Stroke Association, was launched by the Joint Commission. Certification was awarded to primary stroke centers that demonstrated compliance with national standards, primary stroke center recommendations, clinical practice guidelines, and performance measurement and improvement activities. ${ }^{30}$ As of January 1, 2011, there were more than 800 certified primary stroke centers in 49 states. Recently, it was shown that Joint Commission primary stroke center-certified hospitals had lower 30-day risk standardized mortality rates and better outcomes than noncertified hospitals. ${ }^{32,33}$ Large randomized, controlled trials evaluating the efficacy of this certification process and subsequent new standard of care for stroke patients are currently under way.

\section{RATIONALE FOR COE IN PITUITARY TUMOR MANAGEMENT}

\section{Advances in Endoscopic Surgery, Radiosurgery, Endocrinology, Imaging, and Pathology}

Numerous studies over the past 2 decades established that transsphenoidal surgery performed by experienced transsphenoidal neurosurgeons is a safe and effective procedure and the initial treatment of choice for nonfunctioning pituitary adenomas, acromegaly, Cushing's disease, thyroid stimulating hormonesecreting adenomas, pituitary apoplexy, and some prolactinomas, as well as symptomatic Rathke cleft cysts, many craniopharyngiomas, and some clival chordomas.

Advances over the past 15 years in neuroanatomy, surgical technique, microinstrumentation, endoscopy, and surgical navigation have contributed to the rapid evolution of transsphenoidal pituitary surgery into an established subspecialty. Increasingly, pituitary surgery is performed by an endoscopic or endoscopeassisted technique, often in collaboration with ear, nose, and throat surgeons, to maximize visualization of the cranial base, the sella and its contents, and parasellar structures. ${ }^{34-38}$ Although there is some evidence suggesting that endoscopy may help maximize tumor removal, the impact on remission rates, pituitary gland dysfunction, and surgical complications remains under evaluation. ${ }^{36,38-47}$

Paralleling progress in transsphenoidal surgery have been advances in medical therapies for hormonally active pituitary adenomas, particularly in acromegaly ${ }^{48,49}$ and prolactinomas, ${ }^{50}$ as well as better appreciation of hypopituitarism and its treatment paradigms. ${ }^{51,52}$ For patients with pituitary adenomas that are not controlled by surgery or medical therapy, stereotactic radiotherapy and radiosurgery have been shown to be safe and effective secondor third-line therapies. Computer-based targeting techniques have become increasingly sophisticated, allowing safer deliver of radiotherapy not only for residual or recurrent pituitary adenomas and craniopharyngiomas, but also for parasellar meningiomas. ${ }^{53-60}$

Pathological analysis of pituitary tumors has become more and more challenging as novel categories have been defined by the World Health Organization. ${ }^{61-63}$ Although most adenomas may be easily classified, others may be more difficult and require the expertise of a dedicated and experienced neuropathologist, given the potential implications for further treatment. ${ }^{63}$ The molecular signatures of pituitary adenomas using genomics and proteomics are being increasingly used to help indentify invasive and atypical 
adenoma subtypes. ${ }^{64-66}$ Immunohistochemistry, proliferative biomarker studies, and ultrastructural electron microscopic studies have enhanced understanding of tumor behavior and provided new therapeutic targets. Markers such as p53 immunoreactivity, MIB-1 index, and $\mathrm{O}^{6}$-methylguanine-DNA methyltransferase expression are being investigated and increasingly applied in clinical management of patients with atypical or aggressive adenomas. ${ }^{67-70}$ For example, treating aggressive atypical adenomas with the alkylating agent temozolamide has shown initial but variable success and opened potential novel treatment avenues, although $\mathrm{O}^{6}$-methylguanine-DNA methyltransferase expression does not reliably predict responsiveness to temazolamide as it does in glioblastoma. ${ }^{67,68}$

\section{Transsphenoidal Surgery Outcomes and Experience}

As is the case in many areas of surgery, numerous studies show better outcomes and lower complication rates in centers with more experienced transsphenoidal surgeons. ${ }^{71-76}$ Ciric et al ${ }^{77}$ assessed the incidence of complications after transsphenoidal surgery performed by a cross-section survey of US neurosurgeons. Data were gathered through the responses of neurosurgeons to a questionnaire regarding 14 specific complications that was sent to 3172 surgeons; there were 1162 respondents and data from 958 neurosurgeons were analyzed. Among respondents, $87 \%$ reported having performed fewer than 200 procedures, $9.7 \%$ reported 200 to 500 transsphenoidal operations, and $3 \%$ reported more than 500 operations. The incidence of complications was higher with less experienced surgeons, and there was a significant decrease in morbidity and mortality after 200 and 500 transsphenoidal operations. ${ }^{77}$ Ciric et al caution the readers regarding extrapolations of their results because these data rely on the honesty and accuracy of the respondents.

Similarly, Barker et $\mathrm{al}^{78}$ studied the volume-outcome relationship of transsphenoidal surgery for pituitary tumors in a representative sample of US hospitals. This study used the Nationwide Inpatient Sample Hospital Discharge database for the years 1996 to 2000 . The median annual number of operations for pituitary tumors was 10 per hospital or 3 per surgeon. For $23 \%$ of patients, no other transsphenoidal surgery was reported that year by their surgeon. ${ }^{78}$ Patients treated at high-volume hospitals by highvolume surgeons had lower mortality rates, better hospital discharge dispositions, and fewer complications. ${ }^{78} \mathrm{It}$ is important to note that this data source is accurate for endpoints such as mortality and discharge dispositions, but potentially less for complications. Indeed, the coding for such events is known to be incomplete. Furthermore, this data source did not allow Barker et al to evaluate the effect of caseload on surgical efficacy (postoperative endocrine status, visual status).

Other recent studies have confirmed this volume-outcome effect for pituitary tumors as well as for primary and metastatic brain tumors. ${ }^{75,79-82}$ For example, using Nationwide Hospital Discharge database over a 12-year period, Barker et al showed that adult patients undergoing resection or biopsy of primary brain tumors had a lower mortality rate and adverse discharge disposition when treated at higher volume centers compared with lower volume centers. ${ }^{82}$ The impact of accumulating volume and experience was also confirmed in our own experience. Over 10 years with 812 patients with pituitary and other parasellar tumors, complication rates decreased over time; after the initial 500 cases, the incidence of cerebrospinal fluid leaks (3\%-0.8\%), hematomas ( $1 \%-0.3 \%)$, carotid artery injuries $(0.6 \%-0.3 \%)$, and neurological deficits $(0.8 \%-0)$ decreased in the subsequent 312 patients. ${ }^{34}$ Reoperation series also indicate the importance of surgeon experience and likelihood of surgical failure or success. ${ }^{83-85}$ In our own experience of 30 repeat operations for patients with residual endocrineinactive adenomas, suboptimal bony exposure at the sphenoid or sella or both was found in all 30 patients and was thought to be a key factor in subtotal removal at the first operation. ${ }^{84}$

These multiple studies indicate that a high surgical volume allows surgeons to learn from past experience and to apply accumulated knowledge to patient selection, surgical goals, and operative techniques to achieve optimal outcomes and avoid complications. ${ }^{16,34,73,74,76,80,86,87}$ This experience-outcome effect is likely more pronounced in complex cases such as invasive adenomas, reoperations for recurrent adenomas, and other challenging parasellar pathologies such as giant pituitary adenomas, Cushing's disease, craniopharyngiomas, and clival chordomas.

\section{Limitations of Neurosurgical Training in Transsphenoidal Surgery}

Data from the US Accreditation Council for Graduate Medical Education (ACGME) indicate that transsphenoidal surgical experience during residency training may be limited in many US training programs. ${ }^{88}$ Jane et $\mathrm{al}^{88}$ assessed the incidence of pituitary lesions encountered in the ACGME-approved residency training programs as well as the exposure of residents to transsphenoidal surgery. The mean annual number of transsphenoidal operations in US training programs was 39 (range, $7-250$, mode 14 ), with $31 \%$ of training centers performing fewer than 20 transsphenoidal operations per year and $80 \%$ performing fewer than 50 per year. ${ }^{88}$ At the time that this study was reported in 2005, only 7 training centers were performing more than 100 transsphenoidal operations annually. The Residency Review Committee for Neurological Surgery did conclude that most residents finishing approved training programs have limited experience with transsphenoidal surgery, with most graduates having performed a significant part in only 5 to 10 transsphenoidal operations.

A further consideration related to training is the distinct anatomy of the endonasal surgical approach. Understanding ventral, medial, and lateral cranial base anatomy, learning to maneuver instruments and the endoscope through a narrow surgical corridor, maximizing exposure, and achieving effective cranial base reconstruction techniques requires significant practice and training. ${ }^{89,90}$ At the end of residency, many trainees may also have an insufficient experience in pituitary patient management 
including patient selection, surgical technique, and perioperative endocrine management. The results of a survey by the Congress of Neurological Surgeons suggest that additional fellowship training in endonasal transsphenoidal surgery for 6 to 12 months at a high-volume center may be important for residents completing training at a lower volume center who want to have a significant pituitary tumor practice. ${ }^{91}$

Another important consideration is that the overall volume of cases of transsphenoidal surgery is relatively small compared with other areas of neurosurgery. For example, recent data indicate that the total spine surgery and transsphenoidal surgery volumes (all resident years) in US ACGME-approved training programs for 2008 to 2009 were 40861 and 3628, respectively (Neurological Surgery Case Log, National Data Report, 2009). This greater than 10:1 ratio between general spine cases and transsphenoidal cases is also reflected in the overall number of cases performed across the country and further emphasizes that in many training programs, exposure to transsphenoidal surgery is very limited.

\section{Endocrinology Perspective}

Some endocrinologists have expressed their conviction that optimal results for surgical treatment of pituitary tumors are obtained in the hands of experienced surgeons practicing in dedicated centers. ${ }^{92-94}$ Endocrinologists have also recognized their responsibility in choosing the "best" surgeon for their patients, even if this meant referring outside their local service area. ${ }^{93,94}$ They state that finding a skilled pituitary surgeon is not only important for optimal patient care and outcome, but is also economically justified because fewer patients will require adjuvant treatment or reoperation or experience surgical complications. ${ }^{93}$

\section{PROPOSED MISSION OF PITUITARY COES AND RECOGNITION PROCESS}

Given the complexity of pituitary tumors and related hormonal disorders, optimal care for pituitary patients is best provided by experienced practitioners, working in a collaborative environment using state-of-the-art techniques and therapies. In this way, treatment advances in transsphenoidal surgery, endocrinology, radiation oncology, and medical oncology can be focused together to optimize outcomes (Figure). To be recognized as a pituitary $\mathrm{COE}$, we propose that centers fulfill the following 3 primary missions as detailed in Table 3: (1) provide multidisciplinary optimal clinical care to patients with pituitary tumors and related disorders; (2) provide residency, fellowship training, and/or continuing medical education and patient support; (3) contribute to research in the field of pituitary disorders.

As the first mission states, pituitary COEs should aim to provide state-of-the-art care for patients with pituitary tumors and related hormonal disorders using an integrated team approach that includes neurosurgeons; endocrinologists; ear, nose, and throat surgeons; ophthalmologists or neuro-ophthalmologists; radiation oncologists; medical oncologists; and pathologists. Consistent quality of care and management of complex endocrine issues often demand a multidisciplinary approach exemplified by a properly designed and administered COE. Although it is surely possible to deliver optimized care in other less formal settings, the COE model provides an ideal framework to achieve this goal. Regarding neurosurgical expertise, each center should have at least 1 neurosurgeon with considerable transsphenoidal surgical experience after completing residency training and a substantial center case volume. As to what these volume criteria should be is unclear. Perhaps a dedicated work force should be assembled to evaluate whether a specific target number of pituitary disorder patients managed per year or a target number of transsphenoidal operations per year should be used as criteria for recognition of a pituitary COE.

The second proposed mission for each COE is to be involved in training and/or education in pituitary medicine. Such activities could include training residents, fellows, and nurses, as well as participation in pituitary disorder continuing medical education and patient education symposia or support groups. Participation in meetings with special interest in pituitary conditions is another example of how physicians practicing in nonacademic centers can fulfill this mission. Similarly, both stroke certification and trauma center verification require an educational or training component. The Joint Commission grants Primary Stroke Center certification

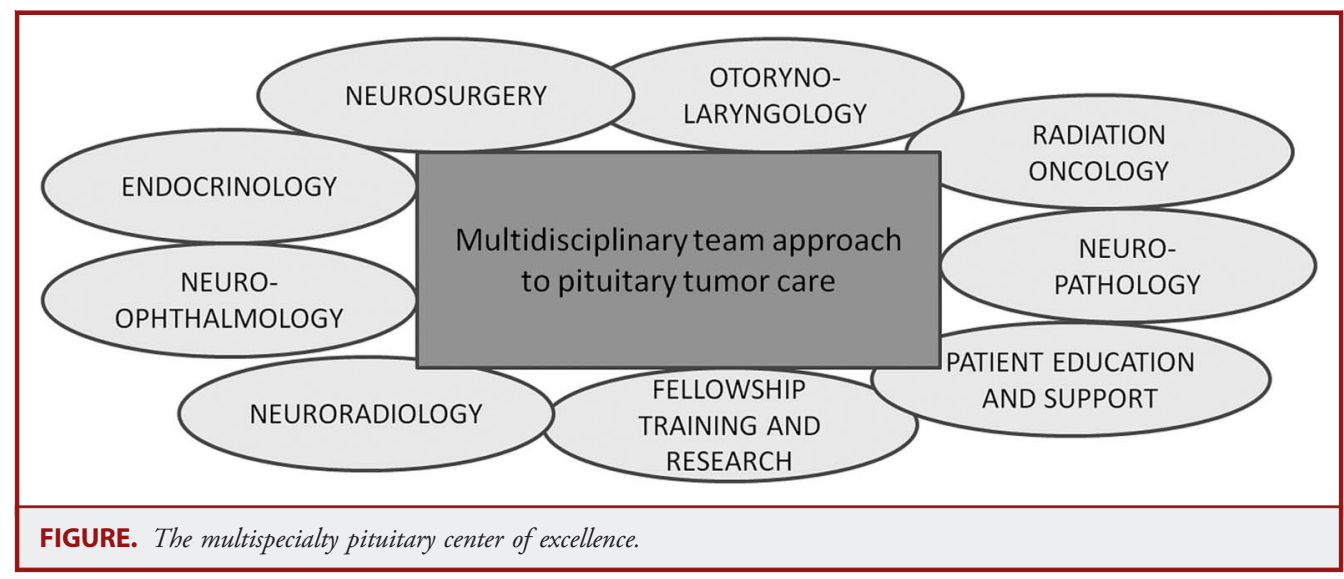


TABLE 3. Pituitary Centers of Excellence: Primary Missions and Criteria for Verification

Provide superior patient care for pituitary disorders

Institutional commitment to excellence

Designated medical director

Sufficient transsphenoidal surgical experience and volumes

Experienced neurosurgeon with established track record in pituitary surgery

Experienced endocrinologist with established track record in pituitary patient care

Multidisciplinary collaboration between neurosurgery; endocrinology; ear, nose, and throat

Neuro-ophthalmology, oncology, radiation oncology, neuroanesthesia, and neuropathology

Prospective data collection documenting caseload, outcomes, and complications

Appropriate equipment and instrumentation for endonasal cranial base surgery including endoscopic equipment

Clinical pathways and standard operating procedures

Nursing staff training in perioperative pituitary tumor patient management and nursing program coordinator

Patient support group and community outreach/education

Provide education and/or training ${ }^{a}$

Residency and/or fellowship training programs

Specialized nursing certifications

Continuous medical education activities

Local community activities to increase awareness of pituitary disorders

Patient support groups

Participation in meetings with special interest on pituitary conditions

Advance the field through research ${ }^{a}$

Translational research

Anatomic studies

Outcomes and quality of life studies

Clinical trials

${ }^{a}$ For educational and research activities, center of excellence verification would not require that all components be met.

based on evaluation of standards, clinical practice guidelines, and performance measurement activities, of which stroke education dedicated to the population is one performance measure. Regarding trauma centers, the verification review committee provides levelspecific criteria to grant certification. The following are examples of criteria that are present in the most recent grid for optimal care: (1) surgeons and specialists who take trauma calls have acquired 16 hours of continuing medical education per year on average or participated in an internal educational process; (2) the trauma center is involved in prevention activities, including public educational activities; and (3) the hospital provides a mechanism for traumarelated education for nurses involved in trauma care.

The third mission calls for COEs to help advance the field of pituitary medicine by participation in research, which may include basic or translational research, epidemiological, or clinical studies. Basic or translational research may be difficult for some institutions; however, all centers could perform retrospective or prospective outcome studies to assess efficacy and safety of surgical, radiation, or endocrine interventions. Additionally, COEs could participate in multicenter clinical projects that would be facilitated by this process of recognition. It will be recommended that COEs also maintain a clinical database of surgically and medically treated patients, their outcomes, and surgical complications. Additionally, participation in national clinical registries and tissue banks should be encouraged. Such clinical databases and collaborative tissue repositories could be used to facilitate large-scale clinical trials to help develop standards of care and best practices and to better understand the genomics and epigenomics of aggressive tumor subtypes. Similar research and database requirements are also part of the American College of Surgeons "Optimal Care for the Injured Patient" as well as by the Brain Attack Coalition under "Recommendations for the Establishment of Primary Stroke Centers." ${ }^{10,31}$ In particular, Level I trauma center verification requires centers to continually expand the body of knowledge in the field of trauma through clinical and basic research programs and fulfill at least 4 of 7 scholarly elements. ${ }^{25-27}$

The mechanism and process for pituitary COE recognition needs to be determined, and possible models could be developed from those used in designation or voluntary verification of trauma centers, stroke centers, and bariatric surgery centers. For example, recognition could be determined by a third party entity similar to the Surgical Review Corporation that oversees bariatric surgery. ${ }^{23}$ Specific requirements for COE recognition could be established by experienced pituitary surgeons, endocrinologists, and radiation oncologists. We recommend that the recognition or verification process be an ongoing process, updated at least biannually. This would ensure that the COEs are continually striving to fulfill their mission. The third-party entity overseeing COE recognition would also encourage and welcome the establishment of new COEs on a regular basis through online society announcements and Websites such as the American Association of Neurological Surgeons, Congress of Neurological Surgeons, the Endocrine Society, and the Pituitary Society.

\section{POTENTIAL IMPLICATIONS AND ISSUES OF PITUITARY COEs}

If the concept of pituitary COE is supported by the neurosurgical and endocrinological communities, several issues still need to be addressed. First, it is not clear which organization, such as the American Association of Neurological Surgeons, the Congress of Neurological Surgeons, the Pituitary Society, the International Society of Pituitary Surgeons, the Endocrine Society, or others, should lead this effort. Second, the organization, function, and funding of the third-party entity that oversees the COE recognition process would need to be structured. Third, the implications of such a process for hospitals with lower volume surgeons and centers that still want or need to perform transsphenoidal surgery are unclear. For example, in patients with pituitary apoplexy and neurological deterioration, urgent transsphenoidal surgery may be indicated, 
and timely transfer to a pituitary COE may not be possible. Although in most instances symptoms and signs of apoplexy evolve over 12 to 24 hours and transfer from one hospital to another hospital is often safe and feasible, the lack of pituitary COE recognition should not preclude centers from providing emergent care. Consequently, it may be important to have a tiered system for pituitary tumor management such as is done for trauma center verification (eg, Level I and II centers) ${ }^{25-27}$ and for stroke center certification (eg, primary and comprehensive Centers). ${ }^{30,31}$ Fourth, establishing pituitary $\mathrm{COE}$ recognition may concentrate expertise in some regions and leave other regions relatively underserved. Means of encouraging the development of new COEs in underserved areas and/or expanding the catchment area of existing COEs may be needed. Indeed, many patients currently travel great distances seeking optimal medical care in various subspecialties of neurosurgery. It would also be important to determine whether COE recognition has measurable benefits in terms of improved patient outcomes and reduced health care costs (eg, higher remission rates, reduced complication rates, less need for adjuvant therapies, and shorter length of stay) that may lead to preferential insurance coverage. ${ }^{95}$ Fifth, it is important to emphasize that although this proposal aims to provide optimized high-quality multidisciplinary care for patients with pituitary disorders, it is not meant to be exclusionary to lower volume neurosurgeons and hospitals. That said, this trend toward centralized or focused care for complex disorders is well under way in many areas of medicine that affect neurosurgery including stroke, trauma, and brain tumor management. ${ }^{25-33,79,82}$ Finally, regarding $\mathrm{COE}$ designation and residency training, because pituitary $\mathrm{COE}$ verification would be a voluntary process and nonverification would not preclude neurosurgeons or hospitals from performing transsphenoidal surgery, the lack of verification would not necessarily limit residency training. Furthermore, the establishment of $\mathrm{COE}$ criteria should be an impetus for all neurosurgical training programs to voluntarily seek verification. This process would undoubtedly enhance their training experience as it pertains to pituitary disorders. For residents in neurosurgical training programs who cannot meet the COE criteria and who want additional training in this area, they should be given the opportunity to perform electives at higher volume pituitary COEs under the supervision of dedicated pituitary surgeons. Certainly, the concept of pituitary $\mathrm{COE}$ recognition will need further thorough validation. A pilot study in currently established high-volume centers may be a reasonable next step. Finally, we acknowledge that this proposal to recognize pituitary COEs is based on observational studies and expert opinions and not on class I evidence.

\section{CONCLUSION}

An abundance of data suggests that optimal management of the pituitary patient requires a coordinated multidisciplinary approach by experienced specialists. Creating an objective recognition process for pituitary COEs would help achieve this goal. The leading neurosurgical and endocrine societies should join together to address this need. Such an effort would enhance patient care, increase public awareness, promote training and expertise, and advance research in the management of pituitary tumors and related hormonal disorders. The participation of pituitary COEs in national clinical registries and tissue banks is key in their mission to significantly contribute to the growth of knowledge of pituitary diseases and help tailor future treatment paradigms. We acknowledge that this preliminary proposal warrants further consideration regarding the verification process including issues of center and surgeon practice volume as well as oversight of the verification process.

\section{Disclosure}

The other authors have no personal financial or institutional interest in any of the drugs, materials, or devices described in this article.

\section{REFERENCES}

1. Couper MP, Singer E, Levin CA, Fowler FJ Jr, Fagerlin A, Zikmund-Fisher BJ. Use of the Internet and ratings of information sources for medical decisions: results from the DECISIONS survey. Med Decis Making. 2010;30(5 suppl): 106S-114S

2. Ilic D. The role of the internet on patient knowledge management, education, and decision-making. Telemed J E Health. 2010;16(6):664-669.

3. Ezzat S, Asa SL, Couldwell WT, Barr CE, Dodge WE, Vance ML, McCutcheon IE. The prevalence of pituitary adenomas: a systematic review. Cancer. 2004;101(3): 613-619.

4. Daly AF, Rixhon M, Adam C, Dempegioti A, Tichomirowa MA, Beckers A. High prevalence of pituitary adenomas: a cross-sectional study in the province of Liege, Belgium. J Clin Endocrinol Metab. 2006;91(12):4769-4775.

5. Fontana E, Gaillard R. Epidemiology of pituitary adenoma: results of the first Swiss study [in French]. Rev Med Suisse. 2009;5(223):2172-2174.

6. Fernandez A, Karavitaki N, Wass JA. Prevalence of pituitary adenomas: a community-based, cross-sectional study in Banbury (Oxfordshire, UK). Clin Endocrinol (Oxf). 2010;72(3):377-382.

7. Hemminki K, Försti A, Ji J. Incidence and familial risks in pituitary adenoma and associated tumors. Endocr Relat Cancer. 2007;14(1):103-109.

8. Raappana A, Koivukangas J, Ebeling T, Pirilä T. Incidence of pituitary adenomas in Northern Finland in 1992-2007. J Clin Endocrinol Metab. 2010;95(9):4268-4275.

9. McDowell BD, Wallace RB, Carnahan RM, Chrischilles EA, Lynch CF, Schlechte JA. Demographic differences in incidence for pituitary adenoma. Pituitary. 2011;14(1):23-30.

10. Biermasz NR, van Thiel SW, Pereira AM, et al. Decreased quality of life in patients with acromegaly despite long-term cure of growth hormone excess. J Clin Endocrinol Metab. 2004;89(11):5369-5376.

11. Hammer GD, Tyrrell JB, Lamborn KR, et al. Transsphenoidal microsurgery for Cushing's disease: initial outcome and long-term results. J Clin Endocrinol Metab. 2004;89(12):6348-6357.

12. Lindholm J, Juul S, Jørgensen JO, et al. Incidence and late prognosis of cushing's syndrome: a population-based study. J Clin Endocrinol Metab. 2001;86(1):117-123.

13. van Aken MO, Pereira AM, Biermasz NR, et al. Quality of life in patients after long-term biochemical cure of Cushing's disease. J Clin Endocrinol Metab. 2005; 90(6):3279-3286

14. Heald AH, Ghosh S, Bray S, et al. Long-term negative impact on quality of life in patients with successfully treated Cushing's disease. Clin Endocrinol (Oxf). 2004; 61(4):458-465.

15. Lindsay JR, Nansel T, Baid S, Gumowski J, Nieman LK. Long-term impaired quality of life in Cushing's syndrome despite initial improvement after surgical remission. J Clin Endocrinol Metab. 2006;91(2):447-453.

16. Laws ER, Jane JA Jr. Pituitary tumors-long-term outcomes and expectations. Clin Neurosurg. 2001;48:306-319.

17. Johnson MD, Woodburn CJ, Vance ML. Quality of life in patients with a pituitary adenoma. Pituitary. 2003;6(2):81-87.

18. Hamilton JJ, Fisher SE. Centers of excellence: an evolving concept-and controversy. Bull AAOS. 2006;54(1). 
19. Weisman CS, Squires GL. Women's health centers: are the National Centers of Excellence in Women's Health a new model? Womens Health Issues. 2000;10(5): 248-255.

20. Champion JK, Pories WJ. Centers of excellence for bariatric surgery. Surg Obes Relat Dis. 2005;1(2):148-151.

21. Hollenbeak CS, Rogers AM, Barrus B, Wadiwala I, Cooney RN. Surgical volume impacts bariatric surgery mortality: a case for centers of excellence. Surgery. 2008; 144(5):736-743.

22. Kohn GP, Galanko JA, Overby DW, Farrell TM. High case volumes and surgical fellowships are associated with improved outcomes for bariatric surgery patients: a justification of current credentialing initiatives for practice and training. $J \mathrm{Am}$ Coll Surg. 2010;210(6):909-918.

23. Pratt GM, McLees B, Pories WJ. The ASBS Bariatric Surgery Centers of Excellence program: a blueprint for quality improvement. Surg Obes Relat Dis. 2006;2(5):497-503; discussion 503.

24. DeMaria EJ, Pate V, Warthen M, Winegar DA. Baseline data from American Society for Metabolic and Bariatric Surgery-designated Bariatric Surgery Centers of Excellence using the Bariatric Outcomes Longitudinal Database. Surg Obes Relat Dis. 2010;6(4):347-355.

25. Jurkovich GJ, Mock C. Systematic review of trauma system effectiveness based on registry comparisons. J Trauma. 1999;47(3 suppl):S46-S55.

26. Mann NC, Mullins RJ, MacKenzie EJ, Jurkovich GJ, Mock CN. Systematic review of published evidence regarding trauma system effectiveness. J Trauma. 1999; 47 (3 suppl):S25-S33.

27. Kelly DF, Becker DP. Advances in management of neurosurgical trauma: USA and Canada. World J Surg. 2001;25(9):1179-1185.

28. Sampalis JS, Denis R, Lavoie A, et al. Trauma care regionalization: a processoutcome evaluation. J Trauma. 1999;46(4):565-579.

29. Chiara O, Cimbanassi S. Organized trauma care: does volume matter and do trauma centers save lives. Curr Opin Crit Care. 2003;9(6):510-514.

30. Alberts MJ, Hademenos G, Latchaw RE, et al. Recommendations for the establishment of primary stroke centers. Brain Attack Coalition. JAMA. 2000; 283(23):3102-3109.

31. Alberts MJ, Latchaw RE, Selman WR, et al; Brain Attack Coalition. Recommendations for comprehensive stroke centers: a consensus statement from the Brain Attack Coalition. Stroke. 2005;36(7):1597-1616.

32. Lichtman JH, Allen NB, Wang Y, Watanabe E, Jones SB, Goldstein LB. Stroke patient outcomes in US hospitals before the start of the Joint Commission Primary Stroke Center certification program. Stroke. 2009;40(11):3574-3579.

33. Lichtman JH, Jones SB, Wang Y, Watanabe E, Leifheit-Limson E, Goldstein LB. Outcomes after ischemic stroke for hospitals with and without Joint Commissioncertified primary stroke centers. Neurology. 2011;76(23):1976-1982.

34. Fatemi N, Dusick JR, de Paiva Neto MA, Kelly DF. The endonasal microscopic approach for pituitary adenomas and other parasellar tumors: a 10-year experience. Neurosurgery. 2008;63(4 suppl 2):244-256; discussion 256.

35. Fatemi N, Dusick JR, Mattozo C, et al. Pituitary hormonal loss and recovery after transsphenoidal adenoma removal. Neurosurgery. 2008;63(4):709-718; discussion 718-719.

36. Schaberg MR, Anand VK, Schwartz TH, Cobb W. Microscopic versus endoscopic transnasal pituitary surgery. Curr Opin Otolaryngol Head Neck Surg. 2010;18(1):8-14.

37. Jane JA Jr, Han J, Prevedello DM, Jagannathan J, Dumont AS, Laws ER Jr. Perspectives on endoscopic transsphenoidal surgery. Neurosurg Focus. 2005;19(6):E2.

38. O'Malley BW Jr, Grady MS, Gabel BC, et al. Comparison of endoscopic and microscopic removal of pituitary adenomas: single-surgeon experience and the learning curve. Neurosurg Focus. 2008;25(6):E10.

39. Zada G, Du R, Laws ER Jr. Defining the "edge of the envelope": patient selection in treating complex sellar-based neoplasms via transsphenoidal versus open craniotomy. J Neurosurg. 2011;114(2):286-300.

40. Dehdashti AR, Ganna A, Karabatsou K, Gentili F. Pure endoscopic endonasal approach for pituitary adenomas: early surgical results in 200 patients and comparison with previous microsurgical series. Neurosurgery. 2008;62(5):10061015; discussion 1015-1017.

41. Dehdashti AR, Gentili F. Current state of the art in the diagnosis and surgical treatment of Cushing disease: early experience with a purely endoscopic endonasa technique. Neurosurg Focus. 2007;23(3):E9.

42. Cappabianca P, Cavallo LM, de Divitiis O, Solari D, Esposito F, Colao A Endoscopic pituitary surgery. Pituitary. 2008;11(4):385-390.
43. Kassis S, De Battista JC, Raverot G, et al. Endoscopy versus microsurgery: results in a consecutive series of nonfunctioning pituitary adenomas [in French]. Neurochirurgie. 2009;55(6):607-615.

44. D’Haens J, Van Rompaey K, Stadnik T, Haentjens P, Poppe K, Velkeniers B. Fully endoscopic transsphenoidal surgery for functioning pituitary adenomas: a retrospective comparison with traditional transsphenoidal microsurgery in the same institution. Surg Neurol. 2009;72(4):336-340.

45. Tabaee A, Anand VK, Barrón Y, et al. Endoscopic pituitary surgery: a systematic review and meta-analysis. J Neurosurg. 2009;111(3):545-554.

46. Rotenberg B, Tam S, Ryu WH, Duggal N. Microscopic versus endoscopic pituitary surgery: a systematic review. Laryngoscope. 2010;120(7):1292-1297.

47. Higgins TS, Courtemanche C, Karakla D, et al. Analysis of transnasal endoscopic versus transseptal microscopic approach for excision of pituitary tumors. $\mathrm{Am} \mathrm{J}$ Rhinol. 2008;22(6):649-652.

48. Manjila S, Wu OC, Khan FR, Khan MM, Arafah BM, Selman WR. Pharmacological management of acromegaly: a current perspective. Neurosurg Focus. 2010;29(4):E14.

49. Chanson P. Emerging drugs for acromegaly. Expert Opin Emerg Drugs. 2008; 13(2):273-293.

50. Casanueva FF, Molitch ME, Schlechte JA, et al. Guidelines of the Pituitary Society for the diagnosis and management of prolactinomas. Clin Endocrinol (Oxf). 2006; 65(2):265-273.

51. Ascoli P, Cavagnini F. Hypopituitarism. Pituitary. 2006;9(4):335-342.

52. Auernhammer CJ, Vlotides G. Anterior pituitary hormone replacement therapya clinical review. Pituitary. 2007;10(1):1-15.

53. de Paiva Neto MA, Vandergrift A, Fatemi N, et al. Endonasal transsphenoidal surgery and multimodality treatment for giant pituitary adenomas. Clin Endocrinol (Oxf). 2010;72(4):512-519.

54. Jane JA Jr, Vance ML, Woodburn CJ, Laws ER Jr. Stereotactic radiosurgery for hypersecreting pituitary tumors: part of a multimodality approach. Neurosurg Focus. 2003;14(5):e12.

55. Jensen R, O'Rourke D, Warnick R, Sawaya R. Resident training in neurosurgical oncology: results of the survey of North American training programs by the AANS/ CNS Section on Tumors. J Neurooncol. 2006;77(3):241-246.

56. Melmed S, Colao A, Barkan A, et al. Guidelines for acromegaly management: an update. J Clin Endocrinol Metab. 2009;94(5):1509-1517.

57. McLaughlin N, Kassam AB, Prevedello DM, Kelly DF. Management of Cushing's disease after failed surgery—a review. Can J Neurol Sci. 2011;38(1):12-21.

58. Sheehan JM, Vance ML, Sheehan JP, Ellegala DB, Laws ER Jr. Radiosurgery for Cushing's disease after failed transsphenoidal surgery. J Neurosurg. 2000;93(5): 738-742.

59. Garré ML, Cama A. Craniopharyngioma: modern concepts in pathogenesis and treatment. Curr Opin Pediatr. 2007;19(4):471-479.

60. Behbehani RS, McElveen T, Sergott RC, Andrews DW, Savino PJ. Fractionated stereotactic radiotherapy for parasellar meningiomas: a preliminary report of visual outcomes. Br J Ophthalmol. 2005;89(2):130-133.

61. Kontogeorgos G. Classification and pathology of pituitary tumors. Endocrine. 2005;28(1):27-35

62. Saeger W, Lüdecke DK, Buchfelder M, Fahlbusch R, Quabbe HJ, Petersenn S. Pathohistological classification of pituitary tumors: 10 years of experience with the German Pituitary Tumor Registry. Eur J Endocrinol. 2007;156(2):203-216.

63. Zada G, Woodmansee WW, Ramkissoon S, Amadio J, Nose V, Laws ER Jr. Atypical pituitary adenomas: incidence, clinical characteristics, and implications. J Neurosurg. 2011;114(2):336-344.

64. Galland F, Lacroix L, Saulnier P, et al. Differential gene expression profiles of invasive and non-invasive non-functioning pituitary adenomas based on microarray analysis. Endocr Relat Cancer. 2010;17(2):361-371.

65. Evans CO, Young AN, Brown MR, Brat DJ, Parks JS, Neish AS, Oyesiku NM. Novel patterns of gene expression in pituitary adenomas indentified by complementary deoxyribonucleic acid microarrays and quantitative RT-PCR. J Clin Endocrinol Metab. 2001;86(7):3097-3107.

66. Moreno CS, Evans CO, Zhan X, Okor M, Desiderio DM, Oyesiku NM. Novel molecular signaling and classification in human clinically non-functional pituitary adenomas identified by gene expression profiling and proteomics analyses. Cancer Res. 2005;65(22):10214-10222.

67. Bush ZM, Longtine JA, Cunningham T, et al. Temozolomide treatment for aggressive pituitary tumors: correlation of clinical outcome with $\mathrm{O}(6)$-methylguanine methyltransferase (MGMT) promoter methylation and expression. J Clin Endocrinol Metab. 2010;95(11):E280-E290. 
68. Syro LV, Ortiz LD, Scheithauer BW, et al. Treatment of pituitary neoplasms with temozolomide: a review. Cancer. 2011;117(3):454-462.

69. Gejman R, Swearingen B, Hedley-Whyte ET. Role of Ki-67 proliferation index and $\mathrm{p} 53$ expression in predicting progression of pituitary adenomas. Hum Pathol. 2008;39(5):758-766

70. Salehi F, Agur A, Scheithauer BW, Kovacs K, Lloyd RV, Cusimano M. Biomarkers of pituitary neoplasms: a review (Part II). Neurosurgery. 2010;67(6):1790-1798.

71. Yamada S, Aiba T, Takada K, et al. Retrospective analysis of long-term surgical results in acromegaly: preoperative and postoperative factors predicting outcome. Clin Endocrinol (Oxf). 1996;45(3):291-298.

72. Gittoes NJ, Sheppard MC, Johnson AP, Stewart PM. Outcome of surgery for acromegaly — the experience of a dedicated pituitary surgeon. QJM. 1999;92(12): 741-745.

73. Erturk E, Tuncel E, Kiyici S, Ersoy C, Duran C, Imamoglu S. Outcome of surgery for acromegaly performed by different surgeons: importance of surgical experience. Pituitary. 2005;8(2):93-97

74. Bates PR, Carson MN, Trainer PJ, Wass JA. Wide variation in surgica outcomes for acromegaly in the UK. Clin Endocrinol (Oxf). 2008;68(1): 136-142.

75. Shahlaie K, McLaughlin N, Kassam AB, Kelly DF. The role of outcomes data for assessing the expertise of a pituitary surgeon. Curr Opin Endocrinol Diabetes Obes. 2010;17(4):369-376.

76. Swearingen B. Update on pituitary surgery. J Clin Endocrinol Metab. 2012;97(4): 1073-1081.

77. Ciric I, Ragin A, Baumgartner C, Pierce D. Complications of transsphenoidal surgery: results of a national survey, review of the literature, and personal experience. Neurosurgery. 1997;40(2):225-236; discussion 236-237.

78. Barker FG 2nd, Klibanski A, Swearingen B. Transsphenoidal surgery for pituitary tumors in the United States, 1996-2000: mortality, morbidity, and the effects of hospital and surgeon volume. J Clin Endocrinol Metab. 2003;88(10): 4709-4719.

79. Barker FG 2nd. Craniotomy for the resection of metastatic brain tumors in the U.S., 1988-2000: decreasing mortality and the effect of provider caseload. Cancer. 2004;100(5):999-1007.

80. Ahmed S, Elsheikh M, Stratton IM, Page RC, Adams CB, Wass JA. Outcome of transsphenoidal surgery for acromegaly and its relationship to surgical experience. Clin Endocrinol (Oxf). 1999;50(5):561-567.

81. Birkmeyer JD, Siewers AE, Finlayson EV, et al. Hospital volume and surgical mortality in the United States. N Engl J Med. 2002;346(15):1128-1137.

82. Barker FG 2nd, Curry WT Jr, Carter BS. Surgery for primary supratentorial brain tumors in the United States, 1988 to 2000: the effect of provider caseload and centralization of care. Neuro Oncol. 2005;7(1):49-63.

83. Laws ER Jr, Fode NC, Redmond MJ. Transsphenoidal surgery following unsuccessful prior therapy. An assessment of benefits and risks in 158 patients. J Neurosurg. 1985;63(6):823-829.

84. Mattozo CA, Dusick JR, Esposito F, et al. Suboptimal sphenoid and sellar exposure: a consistent finding in patients treated with repeat transsphenoidal surgery for residual endocrine-inactive macroadenomas. Neurosurgery. 2006;58(5): 857-865; discussion 857-865.

85. Saeki N, Yamaura A, Numata T. Transsphenoidal reoperations for removal of pituitary adenomas: rhinological management and timing of reoperation. J Clin Neurosci. 1999;6(5):385-388.

86. Jane JA Jr, Laws ER Jr. The surgical management of pituitary adenomas in a series of 3,093 patients. J Am Coll Surg. 2001;193(6):651-659.

87. Wilson CB. Surgical management of pituitary tumors. J Clin Endocrinol Metab. 1997;82(8):2381-2385

88. Jane JA Jr, Sulton LD, Laws ER Jr. Surgery for primary brain tumors at United States academic training centers: results from the Residency Review Committee for neurological surgery. J Neurosurg. 2005;103(5):789-793.

89. Koc K, Anik I, Ozdamar D, Cabuk B, Keskin G, Ceylan S. The learning curve in endoscopic pituitary surgery and our experience. Neurosurg Rev. 2006;29(4) 298-305; discussion 305.

90. Snyderman C, Kassam A, Carrau R, Mintz A, Gardner P, Prevedello DM Acquisition of surgical skills for endonasal skull base surgery: a training program. Laryngoscope. 2007;117(4):699-705.

91. Lee TT, Klose JL. Survey on neurosurgery subspecialty fellowship training. Congress of Neurological Surgeons Education Committee. Surg Neurol. 1999;52 (6):641-644; discussion 644-645.
92. Wass JA, Turner HE, Adams CB. The importance of locating a good pituitary surgeon. Pituitary. 1999;2(1):51-54.

93. Clayton $\mathrm{RN}$. How many surgeons to operate on acromegalic patients? Clin Endocrinol (Oxf). 1999;50(5):557-559.

94. Clayton RN, Stewart PM, Shalet SM, Wass JA. Pituitary surgery for acromegaly. Should be done by specialists. BMJ. 1999;319(7210):588-589.

95. Luft HS, Bunker JP, Enthoven AC. Should operations be regionalized? The empirical relation between surgical volume and mortality. N Engl J Med. 1979;301 (25):1364-1369.

\section{COMMENTS}

7 he authors provide a thoughtful but limited proposal for defining pituitary centers of excellence (PCOEs) for the care of pituitary tumor patients. The justification for this organizational structure is primarily based on a perceived volume-outcome relationship, increasing complexity of pituitary management, and the multidisciplinary care required for these patients. The pillars of the proposed PCOE are optimal patient management, medical education, and research that centers would theoretically facilitate. A fundamental question underlying the authors' proposal is whether centralization of subspecialized neurosurgical care (or any subspecialized medical field) will improve these fundamental aims. COEs seem meritorious, and in fact the increase in academic medical centers took place for these very reasons. However, a distinction must be drawn between patient level and societal level outcomes. Although an individual patient may conceivably receive better care at a PCOE, it does not necessarily follow that a PCOE, which excludes outside clinicians, actually improves the overall health of the population (in this example, that population of patients with pituitary lesions).

Although the association of subspecialization, volume, and outcome has been demonstrated in a number of neurosurgical domains, there is not clear evidence that a systematic centralization of care improves outcome. Thus, the creation of these entities would be based primarily on expert opinion rather than on a strong evidence base. Although a COE strategy has been applied in non-neurosurgical fields with some success, they are not always a panacea. For example, COEs for bariatric surgery have been shown to reduce access to care. Because disparities in access to pituitary resection already exist, such a phenomenon could erode any beneficial effect of increased volume. Moreover, a number of studies have demonstrated that designated COEs do not improve the outcome of bariatric surgery. Therefore, the primary mission of PCOEs, optimal multidisciplinary care, might very well not be fulfilled by the creation of these entities. Furthermore, the additional costs associated with COEs may not be justified. Additionally, as quality metrics become increasingly important and reimbursement becomes more dependent on performance, the development of benchmarks is critical. Although PCOEs could perhaps facilitate collaborative research, mechanisms are being developed to facilitate multicenter, prospective outcomes research. PCOEs may be 1 means of establishing such benchmarks, but certainly with prospective, multicenter observational registries, the field of neurosurgery can derive similar data.

This provocative article will likely generate heated discussion within organized neurosurgery on how to provide the highest level of patient care as well as the implications of the inherent conflict between individual patient care and the greater scope of public health.

Brad E. Zacharia Jeffrey N. Bruce New York, New York 
$\mathrm{n}$ an article that will raise eyebrows along with hackles, the authors propose the designation of pituitary centers of excellence (PCOEs). Such centers would have multidisciplinary expertise in neurosurgery, endocrinology, medical and radiation oncology, neuro-ophthalmology, and neuropathology. The idea is to promote high standards of care, training, and research for a condition that, although not terribly rare, is "fought over," so that experience is diffused widely across the neurosurgical community. As in other surgical conditions and techniques, increasing experience has been found to correlate with better results. So PCOE designation seems like a worthy goal. The authors suggest that such centers should participate in national clinical registries, from which useful outcome data could be gleaned.

Whether to set a minimum number of pituitary surgeries per year as a criterion for designation may remain a matter of controversy because $80 \%$ of American neurosurgical training programs report doing fewer than 50 such operations yearly ( 1 proposed minimum number). On the other hand, the average annual number of cases from such centers is 39 . So, how many transsphenoidal operations are needed by a graduating resident to gain general expertise with the technique and with management of patients with pituitary tumors? If a program sees more than 3 of these patients/cases per month, is that not enough? Surely there are other kinds of surgery that we expect new attendings to do, despite having seen fewer than that number during training.

Thus, the question in the end is begged: is organized surgery, on the whole, not doing a good enough job of training surgeons to manage patients with pituitary tumors? Or is this something that ain't broke and doesn't need fixing?

\section{Michael Schulder}

Manhasset, New York

$\mathrm{T}$ his study lays out a detailed, researched, and reasoned case for establishing a center of excellence (COE) certification process for the treatment of pituitary disease. The key justifications are that (a) the quality of surgical outcomes improve with surgical volume, (b) integrated, multimodality team collaboration by multiple specialties ensures the best treatment decisions, (c) the quality of care can be judged by selected treatment outcome measurements, along with educational and research accomplishments, and (d) most residency training programs do not provide an adequate volume of pituitary cases to prepare residents for independent surgical responsibility.

COE certification can have several advantages. Certification of quality using consensus standards has been customary in improving medical practice since Abraham Flexner surveyed and rated medical schools in 1910, revolutionizing medical education. Certification through the American Board of Medical Specialties member boards, such as the American Board of Neurological Surgery, is widely accepted as a standard of knowledge and training. The American College of Surgeons Trauma Center verification program "validates the resources for trauma care at trauma centers," aiming to set minimum standards for trauma care. As mentioned in this article, the American Society for Metabolic and Bariatric Surgery has provided a certification program for bariatric surgery programs aimed at improving safety and quality since 2004.

On the other hand, the proposal justification and the proposed criteria for pituitary COE certification have several potential problems. First, if successful, the program would divert cases from noncertified programs and practices, reducing their experience even further. Second, it suggests a tiered system of surgical designation similar to stroke and trauma center levels, but surgeons cannot maintain expertise if only performing rare emergency transsphenoidal procedures while diverting routine procedures to the COE. Third, rather than simply to improve quality and outcomes, the proposal suggests the COE designation be used for competitive advantage to gain market share by circumventing usual referral networks and redirecting referrals through Internet publicity or insurer payment differentials for designated centers. Fourth, the COE criteria are more exclusive than the programs to which they are compared (trauma, stroke, bariatric surgery), favoring academic over community programs with the emphasis on training and research criteria. Fifth, the disclaimer that "the proposal. . . is not meant to be exclusionary to lower volume neurosurgeons and hospitals" is misleading because the whole purpose of the proposal is to be just that.

Neurosurgeons have long debated whether complex surgical cases should be concentrated in high-volume academic center programs. The same argument for referral to multidisciplinary centers of excellence can be made for virtually every subspecialty area of neurosurgery: cerebrovascular, glioma, epilepsy, functional, pediatric, complex spine, pain, trauma, brachial plexus, and numerous other anatomic and pathological subcategories. All require coordination of multiple specialties and technical capabilities. All are performed in multiple different practice settings, with different degrees of integration of the participating multimodal specialties. All could potentially be improved by certification of program structure, process, and outcomes. However, no certification process should aim to eliminate competent surgeons and capable practices and programs from treating conditions for which they are qualified by training and experience and inclined by interest.

James R. Bean Lexington, Kentucky

$T$ he authors provide a thoughtful analysis of the development and implementation of pituitary centers of excellence. The authors are correct in recognizing that pituitary and other sellar lesions require a comprehensive treatment team involving the coordinated efforts of surgeons, endocrinologists, radiologists, radiation oncologists, and pathologists. Although the notion of a "center of excellence" has existed within the medical community for several years, its definition and application have varied with little regard for standardization or accreditation. In today's medical environment characterized by heightened scrutiny of individual performance and patient outcome measures, all attempts to clarify the requirements for a center of excellence should be commended. Here, the authors propose strict criteria that define a pituitary center of excellence with particular emphasis on 3 key areas: experienced, multidisciplinary patient care; postgraduate medical education; and focused research endeavors.

Although well intended in both conception and purpose, a system of formal pituitary centers of excellence has several limitations. First, establishment of a third-party regulatory body charged with the initial and continuing accreditation of potential centers involves considerable cost with an as-yet unidentified payer. Funding sources are likely to remain scarce unless a more in-depth cost-effective analysis can demonstrate a center's measurable economic benefit in concrete benchmarks (eg, decreased readmission rates).

Second, and even more important, patient access to adequate medical care could decrease. A center's requirement for residency training limits 
the number of potential sites to 101 neurosurgical training programs in the United States currently approved by the Accreditation Council for Graduate Medical Education. ${ }^{1}$ If centers must then perform at least 50 transsphenoidal procedures each year, only 20 centers remain when factoring the data presented by Jane et al. ${ }^{2}$ When all criteria are met, the number of prospective future centers rapidly decreases. The authors concede potential limitations for a patient in need of emergent/urgent surgery in the somewhat limited case of pituitary apoplexy. However, a more common scenario likely involves the pituitary patient with visual deterioration who is in need of semielective surgery, but presents in a geographically underserved location and is financially unable to travel to a distant center.

Neurosurgeons should always strive to improve the outcomes of our pituitary patients. This mission will continue to include the collaborative efforts of our fellow colleagues from multiple disciplines. However, the large-scale adoption of a pituitary center of excellence model awaits additional economic and medical access data.

Devon Haydon Ralph Dacey, Jr St. Louis, Missouri

1. ACGME Data Resource Book Academic Year 2010-2011, prepared by the ACGME Department of Applications and Data Analysis, released August 2011. http://www.acgme.org/acWebiste/dataBook/2010-2011_ACGME_Data_Resource_ Book.pdf.

2. Jane JA Jr, Sulton LD, Laws ER Jr. Surgery for primary brain tumors at United States academic training centers: results from the Residency Review Committee for neurological surgery. J Neurosurg. 2005;103(5):789-793.

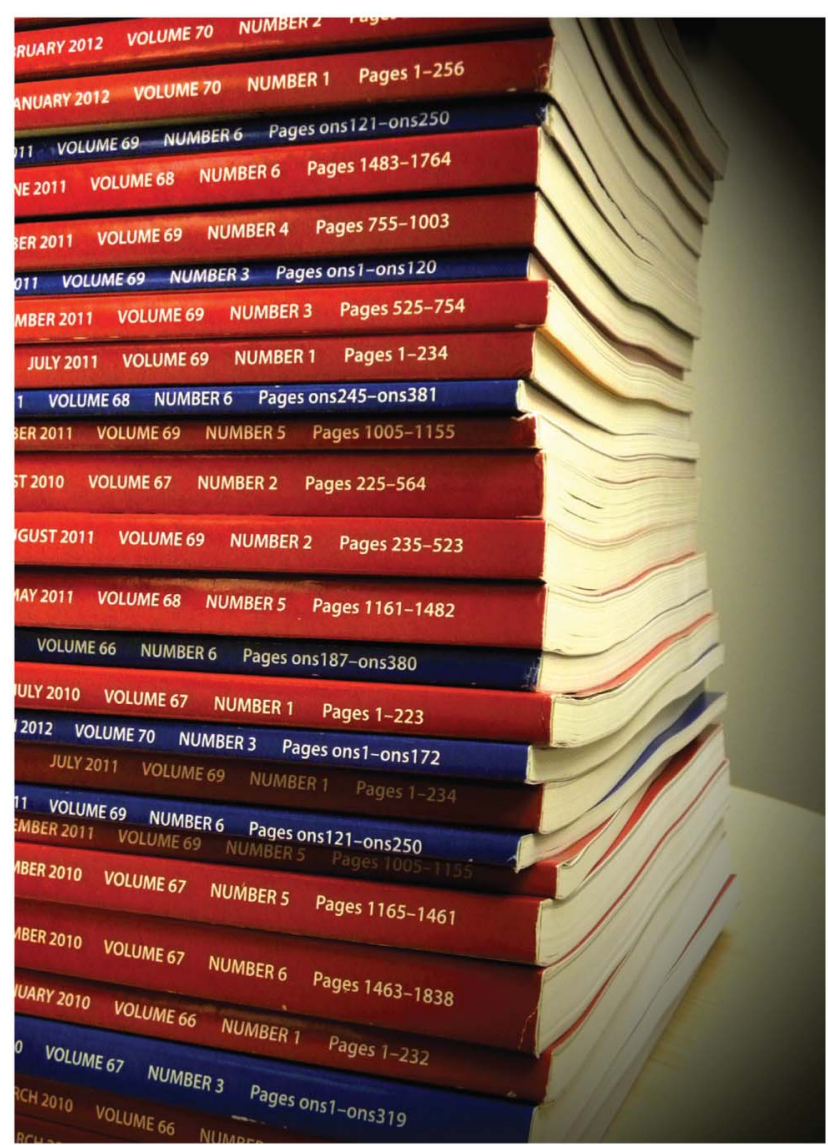

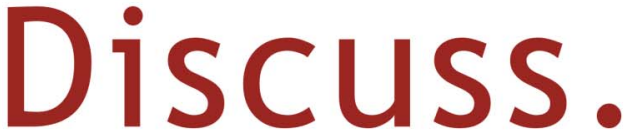

NEUROSURGERY® Journal Club.

This new feature capitalizes on and extends the existing practice of Journal Club common to all neurosurgical training programs where resident and fellows critically review published articles under the guidance of faculty.

For more information, please contact the Neurosurgery Editorial Office by phone at 404.712.5930; or email managingeditor@1cns.org

\section{NEUROSURGERY}

